\title{
Shape memory effect, temperature distribution and mechanical properties of friction stir welded nitinol
}

\author{
S.S. Mani Prabu ${ }^{\text {a, }}{ }^{*}$, H.C. Madhu ${ }^{\text {b }}$, Chandra S. Perugu ${ }^{c}$, K. Akash ${ }^{\mathrm{d}}$, R. Mithun ${ }^{\mathrm{e}}$,

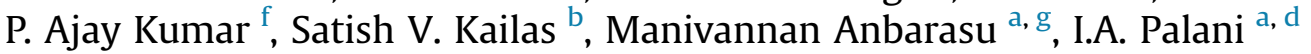 \\ a Metallurgy Engineering and Materials Science, Indian Institute of Technology Indore, Indore, 453552, India \\ ${ }^{\mathrm{b}}$ Department of Mechanical Engineering, Indian Institute of Science, Bangalore, 560012, India \\ ${ }^{c}$ Department of Materials Engineering, Indian Institute of Science, Bangalore, 560012, India \\ ${ }^{\mathrm{d}}$ Discipline of Mechanical Engineering, Indian Institute of Technology Indore, Indore, 453552, India \\ e Mechanical Engineering, A. C. G. College of Engineering and Technology, Karaikudi, 630 003, India \\ ${ }^{\mathrm{f}}$ Department of Materials, University of Wisconsin, Wisconsin, Milwaukee, USA \\ ${ }^{g}$ Discipline of Electrical Engineering, Indian Institute of Technology Indore, Indore, 453552, India
}

\section{A R T I C L E I N F O}

Article history:

Received 1 June 2018

Received in revised form

20 September 2018

Accepted 16 October 2018

Available online 19 October 2018

Keywords:

Shape memory alloy

Nitinol

Friction stir welding

Phase transformation

Temperature distribution

\begin{abstract}
A B S T R A C T
Welding of shape memory alloys without deterioration of shape memory effect could vastly extend their applications. To retain shape memory behavior, a solid-state welding technique called friction stir welding was employed in this study. Austenitic NiTi alloy sheets of thickness $1.2 \mathrm{~mm}$ were joined at tool rotational speeds of 800,1000 , and $1200 \mathrm{rpm}$. Due to dynamic recrystallization, the grain refinement has occurred in the weld region. The tensile testing has shown superelastic plateau for the welds at 800 and $1000 \mathrm{rpm}$. The phase transformation behavior of different weld regions was studied in detail using differential scanning calorimeter. A marginal drift in transformation temperatures was observed in the weld. To understand the drift in phase transformation temperatures, finite element analysis was carried out with focus on temperature distribution during welding. Finally, time-dependent shape recovery of a FSW welded joint was studied and it was found that the original position was completely recovered after $27 \mathrm{~s}$ at a temperature of $65^{\circ} \mathrm{C}$.
\end{abstract}

(C) 2018 Elsevier B.V. All rights reserved.

\section{Introduction}

Nickel-Titanium or Nitinol alloys are widely used shape memory alloys (SMA) due to their exhibition of excellent thermomechanical behavior, pseudoelasticity and biocompatibility. They have been explored in various engineering fields as actuators, sensors, structural elements $[1,2]$ and also as braced frames for seismic retrofitting of civil structures [3]. The applicability of these alloys is limited due to its low formability. Hence, the manufacturing of complex shapes tends to be difficult and expensive. Therefore, the welding becomes inevitable to fabricate NiTi SMA into different geometrical structures with adequate freedom of design. Many conventional and modern fusion welding processes such as gas tungsten arc welding [4,5], plasma welding [6], brazing [7], resistance welding [8], laser welding $[9,10]$ and electron beam welding [11] have been

\footnotetext{
* Corresponding author.

E-mail address: maniprabu.sakthivel@gmail.com (S.S.M. Prabu).
}

used to weld NiTi. Since NiTi SMA is highly sensitive to microstructural and compositional changes, the fusion welding of these alloys leads to deterioration of the mechanical and shape memory properties [12,13]. In fusion welding, due to melting and rapid cooling, dendrite columnar microstructure is formed along with brittle intermetallics [14]. These changes during welding drastically alter the transformational temperatures and reduce the thermomechanical stability of the weld joint.

Recently, we have demonstrated the friction stir welding (FSW) of NiTi alloy with good mechanical properties and retention of shape memory behavior with a minimal change in transformational temperatures [15]. In friction stir welding, the rotating tool having a pin and a shoulder will plunge into the base material and welds it together [16,17]. FSW process produces autogenous weld and the issue of compositional compatibility of filler material with base metal can be ignored [18]. Due to solid state conditions, the distortion and residual stresses will also be minimal compared to fusion welding processes.

During FSW at particular rotational speed, the temperature and 
strain gradient exists across the weld which results in regions such as nugget or stirred zone, advancing side and retreating side [19]. The tool rotational speed is the most influential parameter of the FSW process $[18,20]$. Recently, the influence of tool rotational speed on microstructure and mechanical properties has been reported for materials such as Al-Li alloy and steel [21,22]. As the tool rotation speed increases, the heat induced due to friction between the toolworkpiece interface and the plastic strain energy from intense deformation of workpiece increases. Hence, the tool rotating at higher speed will generate more heat and hence reach higher peak temperature. In addition to the effect on peak temperature, the tool rotational speeds also have impact on strain and strain rate.

As tool rotational speed is major parameter, in this study an attempt has been made to weld NiTi shape memory alloy at three different rotational speeds. The effect of tool rotational speed on the microstructure, phases and mechanical properties of the NiTi alloy has been studied. The phase transformation behavior with respect to the rotational speeds and in different weld regions has been explored. Further, in order to understand the temperature distribution across the weld, the FSW of Nitinol was simulated using finite element method (FEM). The shape memory effect of the welded plate was studied using hot plate actuation technique.

\section{Experimental details}

The austenitic NiTi sheet of $1.2 \mathrm{~mm}$ thickness with Ni 50.75 at.\% (SE508-NDC) was used for welding. The sheets were cut into dimensions $50 \mathrm{~mm} \times 70 \mathrm{~mm}$ and welded using five-axis FSW machine (BiSS-ITW Bangalore) in closed square butt configuration.

Experiments were conducted at three rotational speeds ( $800 \mathrm{rpm}, 1000 \mathrm{rpm}$ and $1200 \mathrm{rpm}$ ) with constant traverse speed of $50 \mathrm{~mm} / \mathrm{min}$ in the ambient environment without any cooling medium or shielding gas. A tungsten alloy (densimet) tool was used for welding. Microstructure, mechanical and shape memory properties of the welds were characterized. Fig. 1 shows the schematic of FSW and process parameters used for welding.

The samples for microstructural analysis were polished using various grits of $\mathrm{SiC}$ paper, then using alumina powder and finally etched using $50 \mathrm{~mL} \mathrm{H}_{2} \mathrm{O}+40 \mathrm{~mL} \mathrm{HNO}_{3}+10 \mathrm{~mL} \mathrm{HF}$ solution. The microstructures were recorded using Carl Zeiss inverted optical microscope. The phase analysis was carried out by X-ray diffraction (XRD) technique using X-Pert PRO PANalytical. Further, tensile test samples with a cross section of $1.2 \mathrm{~mm} \times 4 \mathrm{~mm}$ were machined across the weld. Tensile test was carried out on Instron-5967 machine at a strain rate of $10^{-3}$. Vickers microhardness measurements were taken along the cross section of the weld using the FM-800 Future Tech Corp at $500 \mathrm{gf}$ load for $15 \mathrm{~s}$. The characterization techniques to evaluate the microstructures, phases, hardness and stress-strain behavior were performed at room temperature.

Samples were cut from nugget, retreating side and advancing side of the weld joint (Fig. 2) for studying the phase transformation behavior using differential scanning calorimetry (DSC). The phase transformation behavior was studied using Netzsch-DSC214 Polyma DSC machine at a heating/cooling rate of $10^{\circ} \mathrm{C} / \mathrm{min}$ with a constant flow of nitrogen.

The FSW of Nitinol has been simulated using Comsol Multiphysics 5.3a based on FEM. To study the shape memory effect, the welded samples were annealed at $475^{\circ} \mathrm{C}$ for $1 \mathrm{~h}$ and then furnace cooled to room temperature. A strip of dimension $65 \mathrm{~mm} \times 2 \mathrm{~mm} \times 1.2 \mathrm{~mm}$ was cut across the weld and used for actuation studies.

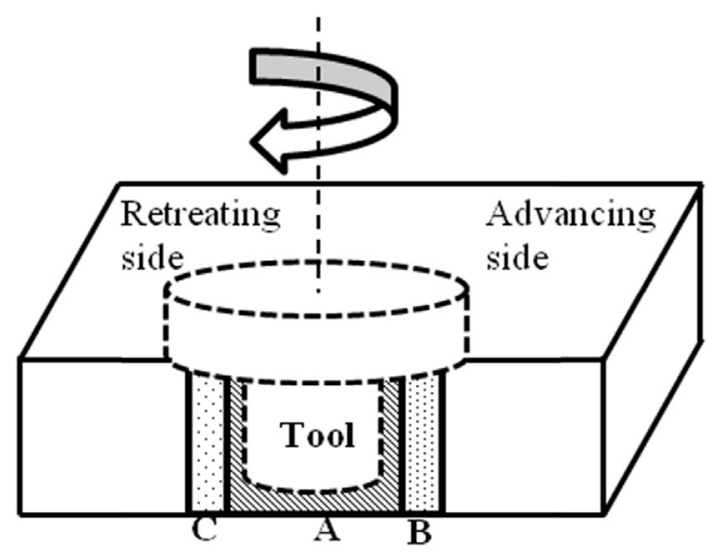

Fig. 2. Schematic of the DSC sample regions (A-Nugget, B-Advancing side and CRetreating side).

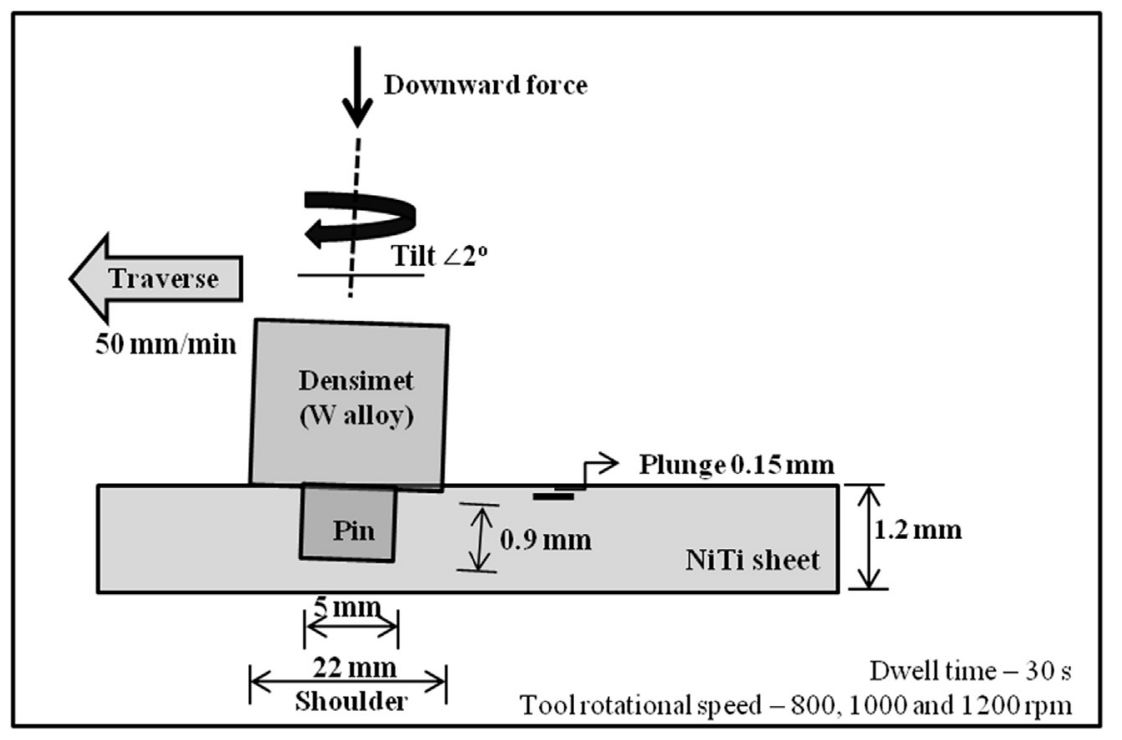

Fig. 1. FSW process and the process parameters used for welding. 


\section{Theoretical analysis}

The model used for the study was based on the work done by Song et al. [23]. The heat input from both the tool pin and shoulder was considered. The governing equation of heat generation in pinworkpiece (Qpin) considering the evolution of heat due to shearing of the workpiece and friction is given by,

$Q_{\text {pin }}=\frac{2 \pi n \mu}{\sqrt{3\left(1+\mu^{2}\right)}} \bar{Y} R_{p}$

The heat generation at the shoulder-workpiece $\left(\mathrm{Q}_{\text {shoulder }}\right)$ interface is given by,

$Q_{\text {shoulder }}=2 \pi \mu \frac{F_{n}}{A_{\text {shl }}} R_{s} n$

Where $\mu$-coefficient of friction, $\mathrm{R}_{\mathrm{s}}$-shoulder radius ( $\mathrm{mm}$ ), $\mathrm{F}_{\mathrm{n}}$-plunge force $(\mathrm{KN}), \mathrm{A}_{\mathrm{shl}}$-surface area $\left(\mathrm{mm}^{2}\right)$, n-tool rotational speed (RPM), $\bar{Y}$-average shear stress of the material and $\mathrm{R}_{\mathrm{p}}$-pin radius $(\mathrm{mm})$.

On heat generation due to the rotation of the tool, the heat will transfer from the vicinity of the weld to the surrounding via both convective and radiative mode of heat transfer. The governing heat transfer equations for conductive heat transfer in the material (Q) and convective-radiative heat transfer from the workpiece is given by the following equations.

$\rho C_{p} u \bullet \nabla T=\nabla \bullet(k \nabla T)+Q$

$Q=h A\left(T_{0}-T\right)$

$Q=\varepsilon \sigma\left(T_{0}^{4}-T^{4}\right)$

Where $\rho$-density $\left(\mathrm{Kg} / \mathrm{m}^{3}\right), \mathrm{C}_{\mathrm{p}}$-specific heat $(\mathrm{J} / \mathrm{Kg} \mathrm{K})$, u-welding speed $(\mathrm{mm} / \mathrm{min})$, k-thermal conductivity $(\mathrm{W} / \mathrm{m} \mathrm{K})$, h-heat transfer coefficient $\left(\mathrm{W} / \mathrm{m}^{2} \mathrm{~K}\right)$, A-surface area of exposed surface $\left(\mathrm{mm}^{2}\right)$, $\varepsilon$-surface emissivity, $\sigma$-Stefan-Boltzmann constant and $\mathrm{T}_{0}$-ambient temperature.

\section{Results and discussion}

\subsection{FSW and microstructural evaluation}

The macroscopic images of the welds produced at 800,1000 and $1200 \mathrm{rpm}$ are shown in Fig. 3a-c. All the welds had proper consolidation of the joint without any surface defects. The macrostructure of the weld cross section was shown in Fig. 3d. The zone A-B represents the transition zone from shoulder region to base metal on advancing side and retreating side of the weld respectively.

The microstructures of the base metal and the weld are shown in Fig. 4. The base metal has equiaxed coarse grains. The microstructure of the weld region for all the tool rotational speeds has fine recrystallized grains. The recrystallized grains were found throughout the weld and there was no clear distinction between nugget, thermo-mechanically affected zone (TMAZ) and heat affected zone (HAZ). Generally, the dynamic recrystallization takes place in the metals when subjected to hot working and it depends upon the peak temperature, plastic strain, strain rate and stacking energy of the materials [24]. In metals with high stacking fault energy like NiTi, the continuous dynamic recrystallization occurs when the temperature is greater than $50 \%$ of the melting point $[25,26]$. During FSW, the frictional heat and plastic deformation caused by the tool rotation induces the welding temperature of approximately $0.7-0.8$ times the melting point of the material [27]. Hence, the continuous dynamic recrystallization accompanied with dynamic recovery has resulted in the formation of refined elongated grains during FSW of NiTi alloy [20]. In the weld at particular tool rotational speed, the temperature and plastic deformation in the adjacent regions to the nugget are lower than the nugget zone. Due to this, the recrystallization does not take place outside the nugget for most of the materials. However, in NiTi alloy, even at lower strain and higher temperature recrystallization will occur [28]. This has resulted in the formation of recrystallized grains in TMAZ and HAZ and all the regions exhibited homogeneous microstructure.

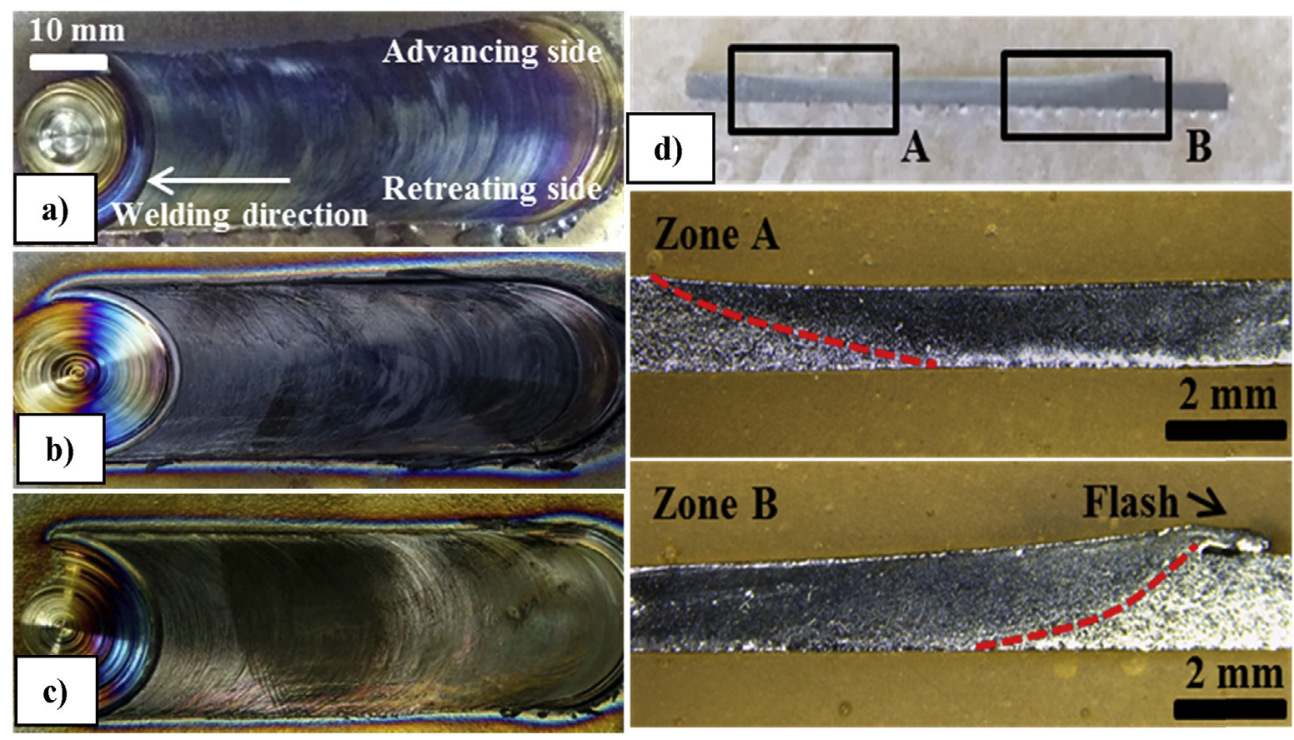

Fig. 3. Defect free friction stir welds at a) $800 \mathrm{rpm}$ and b) $1000 \mathrm{rpm} \mathrm{c}) 1200 \mathrm{rpm}$ and d) Macrostructure of the weld cross section. 


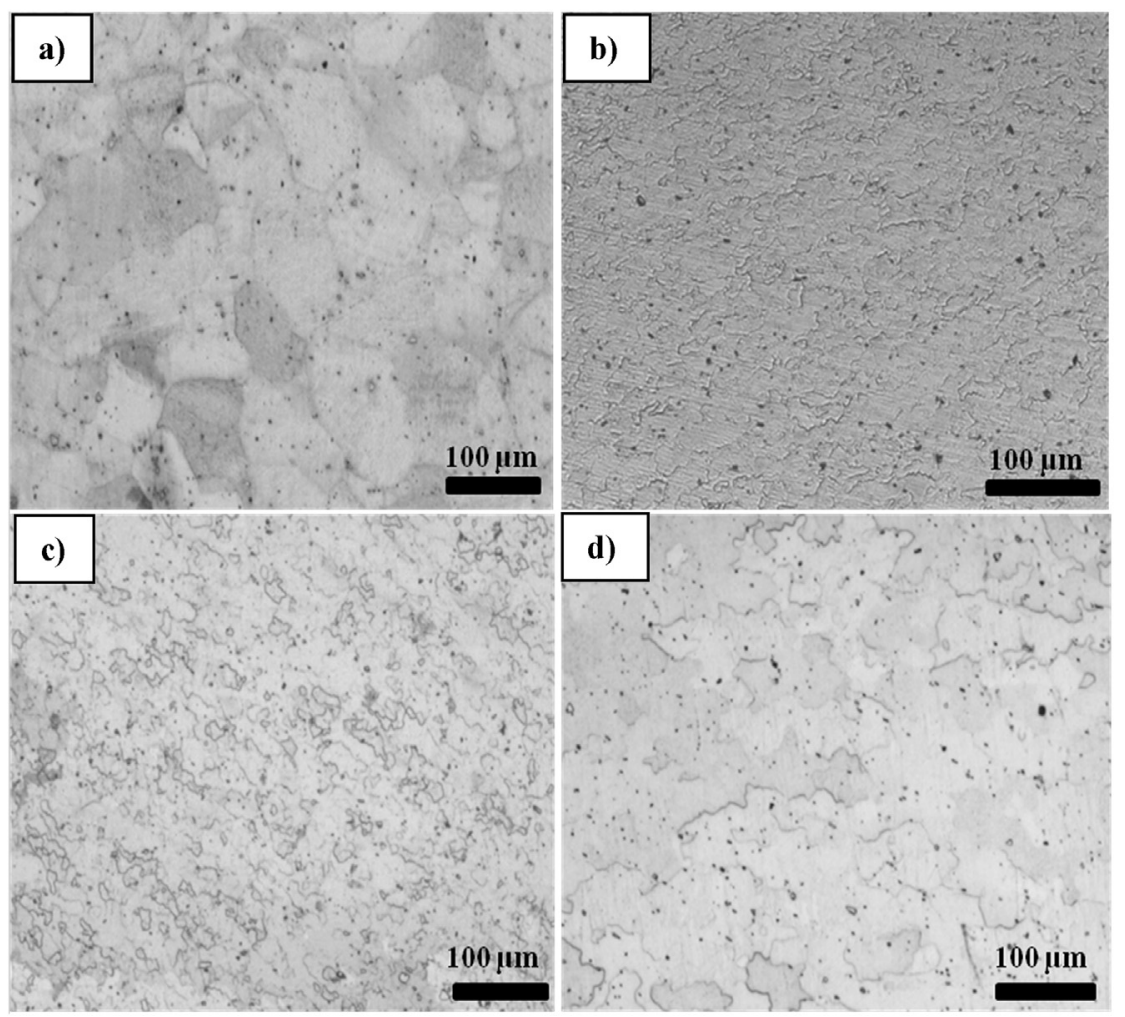

Fig. 4. Microstructures of the NiTi alloy before and after welding a) Base metal, b) weld nugget at $800 \mathrm{rpm}$, c) weld nugget at $1000 \mathrm{rpm}$ and d) weld nugget at $1200 \mathrm{rpm}$.
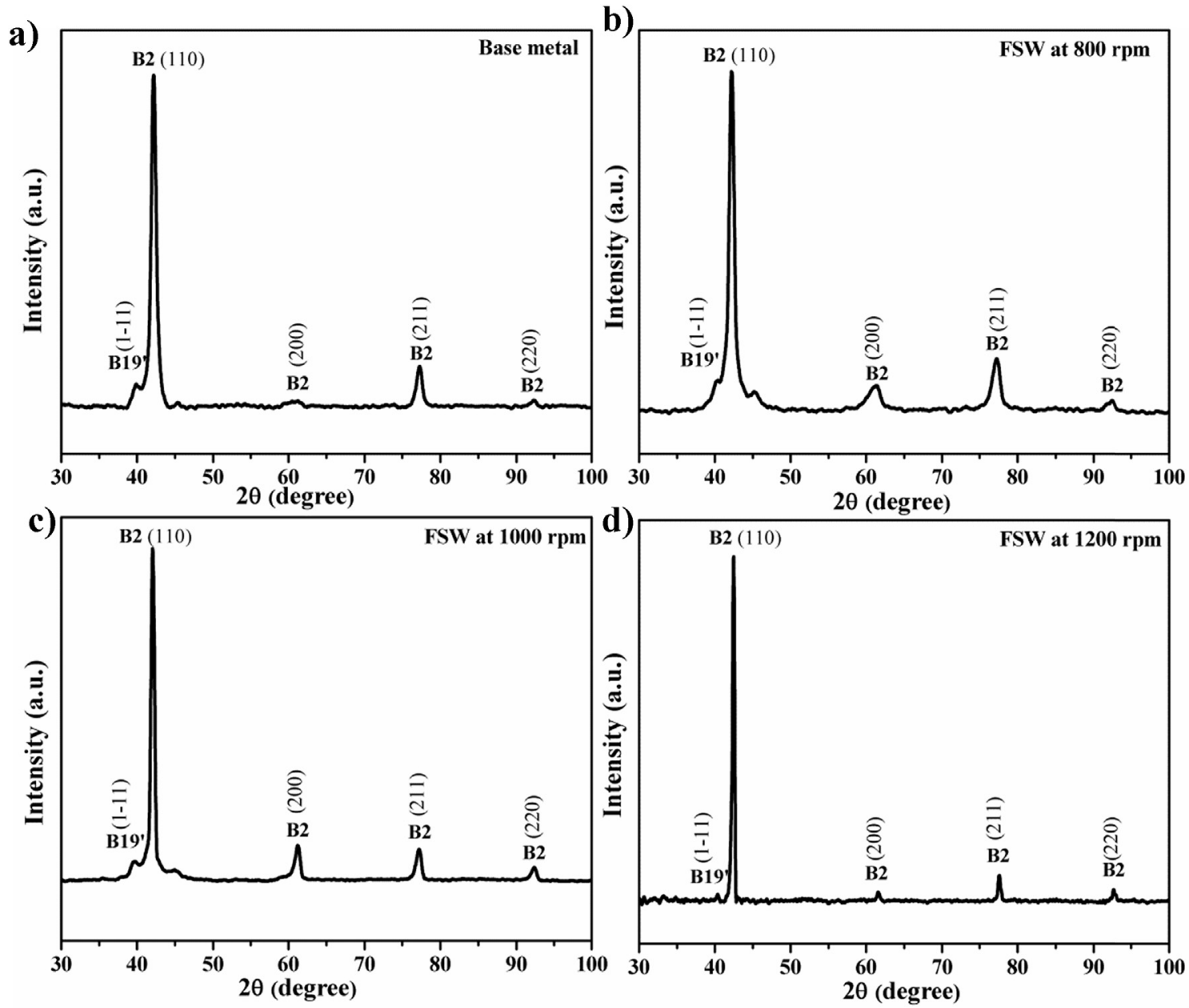

Fig. 5. XRD patterns of NiTi alloy before and after welding a) Base metal, b) FSW at $800 \mathrm{rpm}, \mathrm{c})$ FSW at $1000 \mathrm{rpm}$ and d) FSW at $1200 \mathrm{rpm}$. 


\subsection{XRD analysis}

The XRD patterns of the base metal and weld regions at different rotational speeds are shown in Fig. 5. The base metal and the weld at three different tool rotational speeds have austenite (B2-cubic) phase with traces of martensite (B19'-monoclinic) phase. Intermetallic compounds $\left(\mathrm{NiTi}_{2}\right.$ and $\left.\mathrm{TiNi}_{3}\right)$ commonly observed in fusion welding of NiTi and are detrimental to shape memory behavior were absent. Further, interestingly phases of the base metal have been retained even after welding. However, in case of electron beam and laser beam welding, transformation between the martensite and austenite phases after welding was generally observed [11,29].

\subsection{DSC analysis}

The DSC curves of the base metal and the weld nuggets at different tool rotational speed are shown in Fig. 6. $A_{s}, A_{f}, M_{s}$ and $M_{f}$ are the austenite-martensite start and finish transformation temperatures. These transformation temperatures are given as an inset in Fig. 6. The DSC curves of base metal and weld nuggets at 800 and $1000 \mathrm{rpm}$ depict the exothermic peaks during the forward transition from austenite to martensite $\left(\mathrm{B} 2 \rightarrow \mathrm{R} \rightarrow \mathrm{B} 19^{\prime}\right.$ or $\left.\mathrm{B} 2 \rightarrow \mathrm{B} 19^{\prime}\right)$ on cooling. Further, they depict the endothermic peaks during the

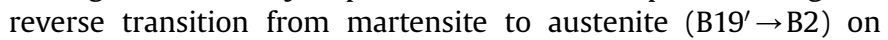

heating. Fig. 6d shows the DSC curve of the weld nugget at $1200 \mathrm{rpm}$ during heating and cooling cycles. The transformational temperatures of the base metal and weld nugget of $800 \mathrm{rpm}$ were very close to each other. However, the martensite transformation temperatures $\left(M_{S}\right.$ and $\left.M_{f}\right)$ of weld nuggets of 1000 have increased after welding. Figs. 7 and 8 shows the DSC curves of advancing and retreating side of the weld at different tool rotational speeds. The phase transformation temperatures of both sides of weld at $800 \mathrm{rpm}$ were close to the base metal. But the martensite transformation of both sides of the weld at $1000 \mathrm{rpm}$ has shown a drift towards the positive direction. In case of the weld at $1200 \mathrm{rpm}$, the transformations are different and unusual from the base metal and the other welds. So, these transformations are represented as $\mathrm{T}_{\mathrm{s}}$ and $\mathrm{T}_{\mathrm{f}}$ during heating and cooling cycles respectively. This unusual pattern could plausibly due to microstructural heterogeneities and tool inclusions across the weld regions.

FSW is a thermo-mechanical process which involves high temperature and severe plastic deformation. As it was seen from the microstructures (Fig. 4) of welds at different tool rotational speeds, grain size of the nugget varied considerably. Further, it can be assumed that the dislocation density and the residual stress of the weld at a particular tool rotational speed will be different. As phase transformational behavior is sensitive to dislocation density, grain size and residual stress, the friction stir welded NiTi has exhibited a drift in phase transformational temperatures [30]. Due
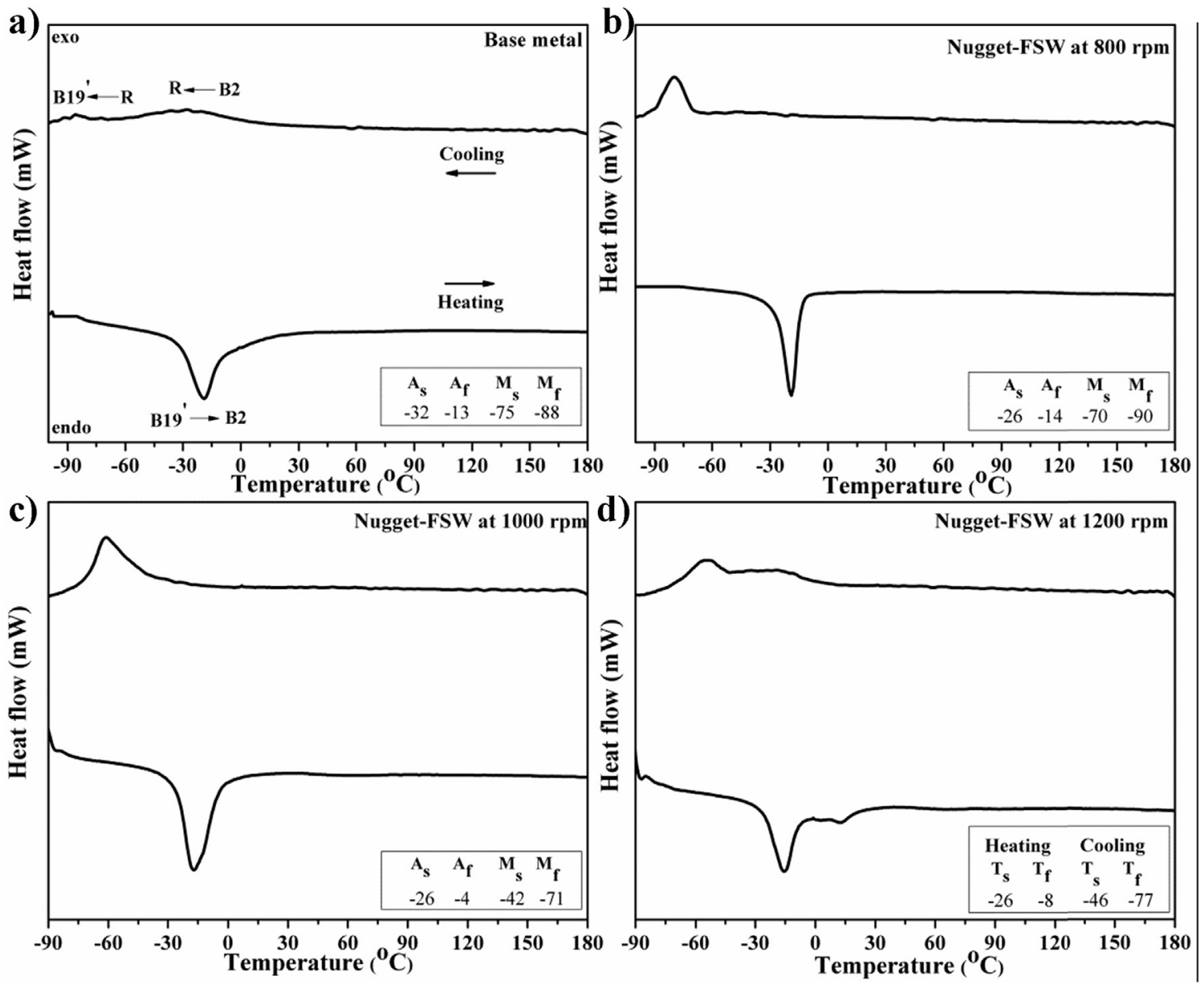

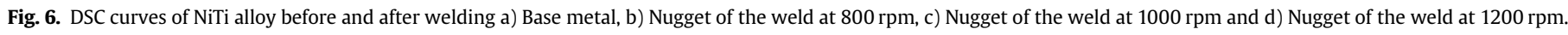


to high plastic deformation in the nugget zone, the temperature rise is comparably higher than the advancing and retreating sides $[18,20]$. However, the zones next to the nugget i.e. both TMAZ and HAZ experiences low to negligible plastic deformation and lower temperatures than the nugget zone. Hence during FSW, an inherent asymmetry in temperature, strain and strain rate exits across the weld. Typically, the advancing side encounters higher temperature and shearing rates than the retreating side [19]. This asymmetry in the temperature and plastic deformation across the weld regions may cause difference in dislocation density and residual stress which has led to change in phase transformation temperatures in different weld regions [28].

The hysteresis due to dissipative work is the interval between heating and cooling transformations i.e. $|\mathrm{As}-\mathrm{Mf}|$ and $|\mathrm{Ms}-\mathrm{Af}|$ [31-33]. The hysteresis for the base metal and the weld at different rotational speed is given in Table 1 . The hysteresis $\left(A_{s}-M_{f}\right)$ has reduced for weld at 1000 whereas increased for the weld produced at $800 \mathrm{rpm}$.

\subsection{Microhardness and tensile analysis}

Microhardness of the weld cross section and scanning electron microscope (SEM) images of the weld at $1200 \mathrm{rpm}$ is shown in Fig. 9. The average hardness of the weld at $800 \mathrm{rpm}, 1000 \mathrm{rpm}$ and $1200 \mathrm{rpm}$ were 275 HV, 262 HV and 284 HV respectively. Few abnormally high hardness values were noticed in $1200 \mathrm{rpm}$ weld due to tool fragments (Fig. 9b) included and distributed across the weld region. The distribution of tool fragments across the weld could be attributed to the severe plastic deformation and high temperature experienced at $1200 \mathrm{rpm}$ than the other rotational speeds. The weld at $800 \mathrm{rpm}$ and $1000 \mathrm{rpm}$ has showed marginally lower hardness than the base metal (BM).

Fig. 10 shows the engineering stress-strain curve of the base metal and the welds. The weld produced at $800 \mathrm{rpm}$ has displayed an ultimate tensile strength of $492 \mathrm{MPa}$ and yield strength of $453 \mathrm{MPa}$. Interestingly, the weld produced at $1000 \mathrm{rpm}$ had ultimate tensile strength of $638 \mathrm{MPa}$ (66\% of the BM) and yield strength of $602 \mathrm{MPa}$ which is $17 \%$ higher than the base metal. The weld at $1000 \mathrm{rpm}$ has a crucial superelastic plateau near $600 \mathrm{MPa}$ until $7.25 \%$ strain while the weld at $800 \mathrm{rpm}$ showed close to $460 \mathrm{MPa}$ until $5 \%$ strain. Ultimate strength of the weld at $1200 \mathrm{rpm}$ was $345 \mathrm{MPa}$ which was lower among the welds produced due to the presence of hard tool fragments. The cross section of the weld (Fig. 10b), shows cracks close to the tool fragments which could be attributed to inhomogeneous material flow and mismatch in thermal expansion between the tool fragments and the NiTi.

In case of welding of shape memory alloys, the retainment of crucial superelastic plateau (functional property), yield strength and ultimate tensile strength are the factors defining the quality of the weld. The FSW of nitinol has shown better yield strength (due to grain refinement) than base metal at $1000 \mathrm{rpm}$ and the welds at 800 and $1000 \mathrm{rpm}$ has shown crucial superelastic plateau. It is important that the FSW has shown higher yield strength (compared to base metal) than most of the reported welding


Fig. 7. DSC curves of advancing side of friction stir welded NiTi alloy a) FSW at $800 \mathrm{rpm}$, b) FSW at $1000 \mathrm{rpm}$ and c) FSW at $1200 \mathrm{rpm}$. 

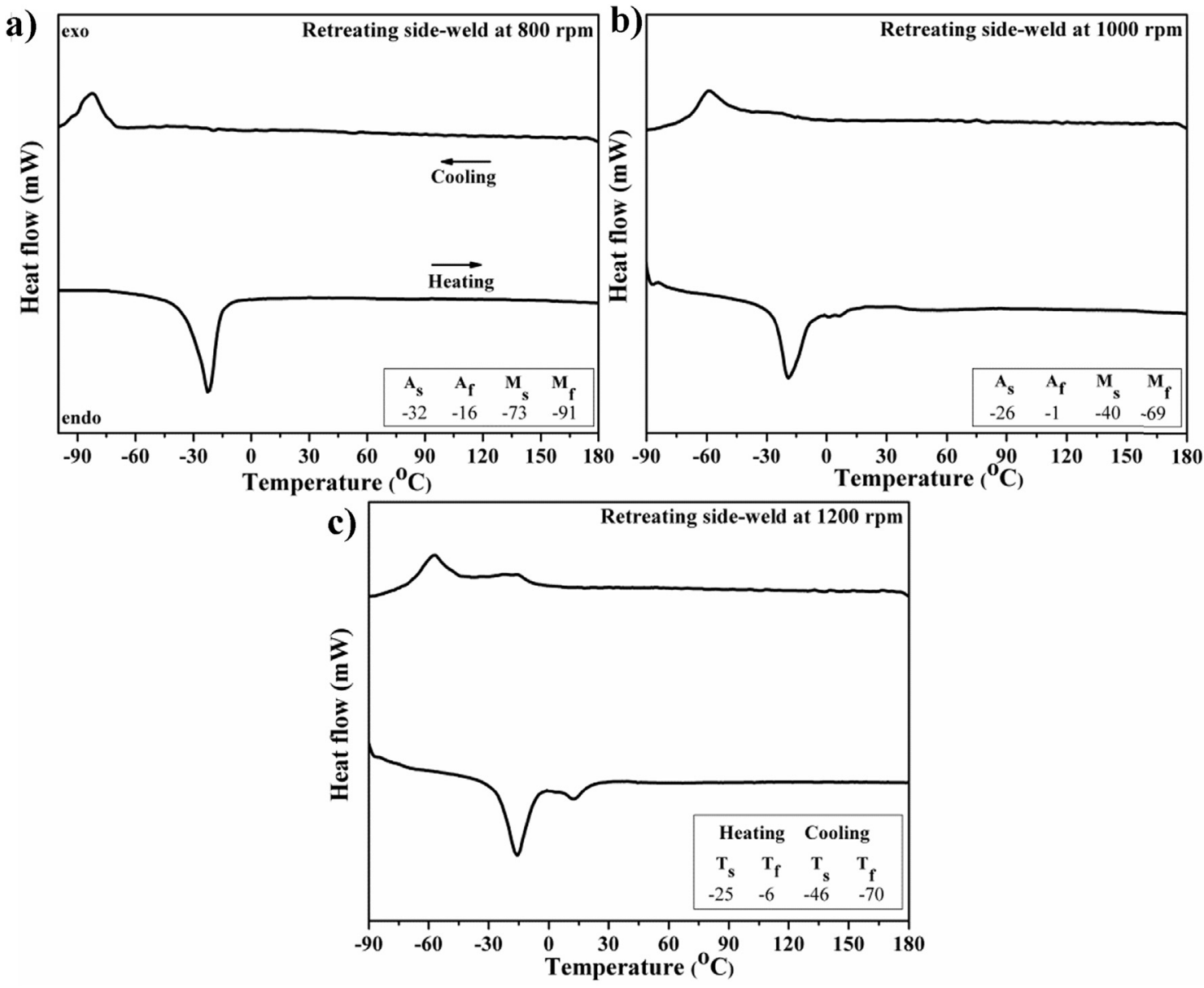

Fig. 8. DSC curves of retreating side of friction stir welded NiTi alloy a) FSW at $800 \mathrm{rpm}$, b) FSW at $1000 \mathrm{rpm}$ and c) FSW at $1200 \mathrm{rpm}$.

Table 1

Hysteresis of the phase transformation behavior at different regions of the weld.

\begin{tabular}{lll}
\hline Weld region & Process conditions & $\mid$ As $-\mathrm{Mf} \mid\left({ }^{\circ} \mathbf{C}\right)$ \\
\hline \multirow{2}{*}{ Nugget } & Base metal & 56 \\
& $800 \mathrm{rpm}$ & 64 \\
Advancing side & $1000 \mathrm{rpm}$ & 46 \\
& $1200 \mathrm{rpm}$ & - \\
Retreating side & $800 \mathrm{rpm}$ & 61 \\
& $1000 \mathrm{rpm}$ & 58 \\
& $1200 \mathrm{rpm}$ & - \\
& $800 \mathrm{rpm}$ & 49 \\
& $1000 \mathrm{rpm}$ & - \\
\hline
\end{tabular}

techniques such as electron beam welding, laser welding, tungsten arc welding [4,34-36]. On the other hand, the ultimate tensile strength depends on the bonding of the weld joint and the week point across the weld structure acts as the nucleating point for fracture. In FSW of nitinol, the interface between the base metal and the weld region (transition zone from refined grains of weld to coarse grains of base metal) acts as weak point for the fracture. All the welded samples have broken at heat affected zone i.e. the week interface zone. So, the joint efficiency can be improved by further detailed optimization on tool selection, tool geometry design and process parameters to enhance the plasticization of material across the weld zones.

The fracture surfaces of the weld and the BM observed using scanning electron microscope are shown in Fig. 11. The fracture surface of the BM and the welds except at $1200 \mathrm{rpm}$ showed dimples indicating ductile fracture. The fracture surface of the weld at $1200 \mathrm{rpm}$ show smooth surface indicative of brittle fracture. Further, the micro cracks which could have been originated at the tool fragments are seen in Fig. 11d.

\subsection{Shape memory effect}

Since the weld at $1000 \mathrm{rpm}$ showed better mechanical properties, it has been used for actuation studies. The welded sample was annealed at $475^{\circ} \mathrm{C}$ for one hour before the actuation studies. The phase transformation behavior after annealing is shown in Fig. 12. Annealing has converted the welded NiTi from superelastic state to shape memory state i.e. from austenite to martensite at room temperature. Strain was imposed in the welded sample to bend to a $\mathrm{U}$ shape in an ice bath. After bending, the sample was actuated on a hot plate held at $65^{\circ} \mathrm{C}$. This temperature was chosen as it was above the austenite finish temperature of the sample. The sample was not disturbed until imposed strain was completely recovered. The actuation was quantified using recovery angle, which is the angle between two tangents drawn $5 \mathrm{~mm}$ from the weld center on either 

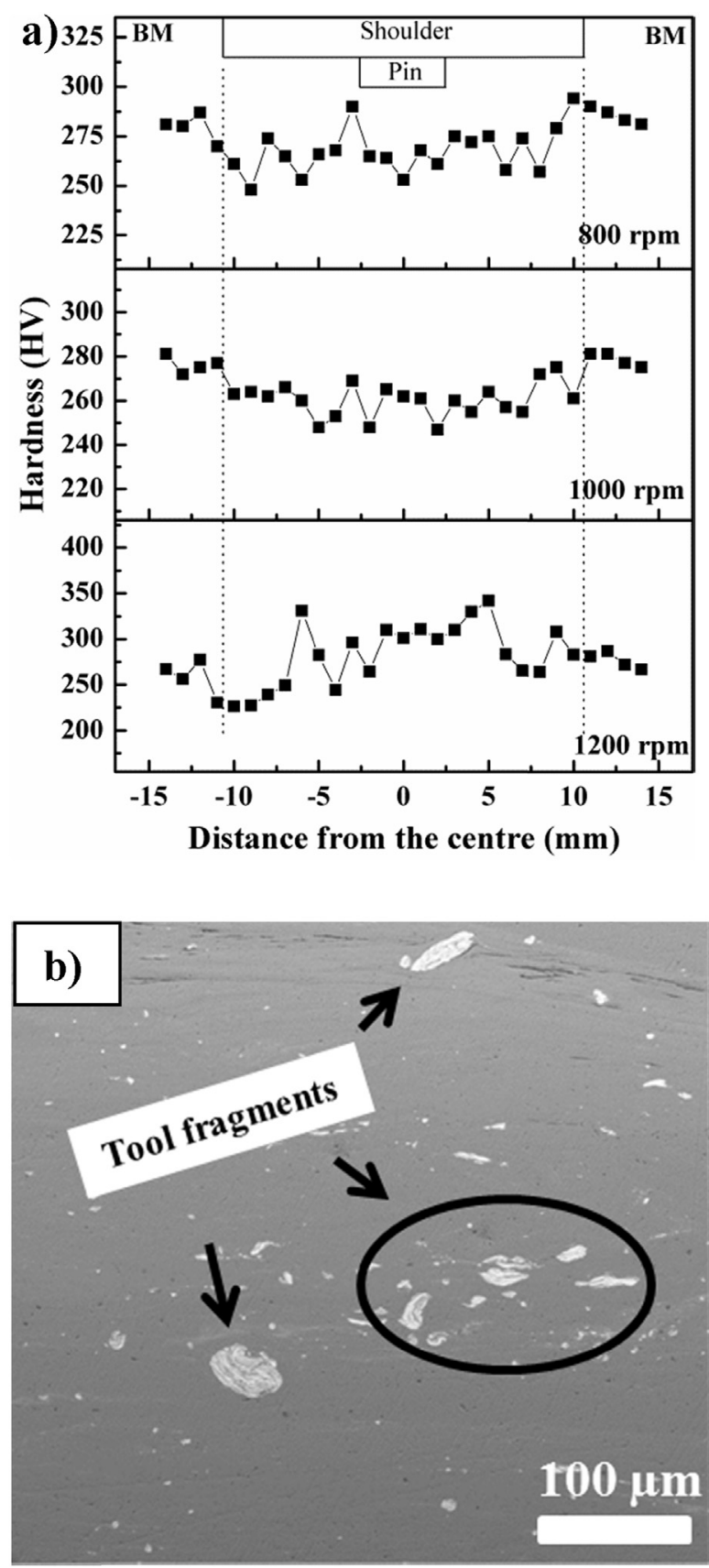

Fig. 9. a) Microhardness of the weld cross section and b) Cross sectional SEM images of the weld at $1200 \mathrm{rpm}$ showing tool fragments.

side. The recovery angle was measured using the AutoCAD software from the images acquired during actuation. The method of angle measurement was similar to the method reported by J. P. Oliveira [37]. The duration for complete strain recovery was noted to be $27 \mathrm{~s}$, beyond which there was no change in the sample. The load applied for bending will convert the sample from twinned martensite into detwinned martensite. On heating, austenite transformation starts and the sample will return to initial straight position. The schematic of angle measurement, recovery angle vs time plot and snapshots of the actuation are shown in Fig. 13.

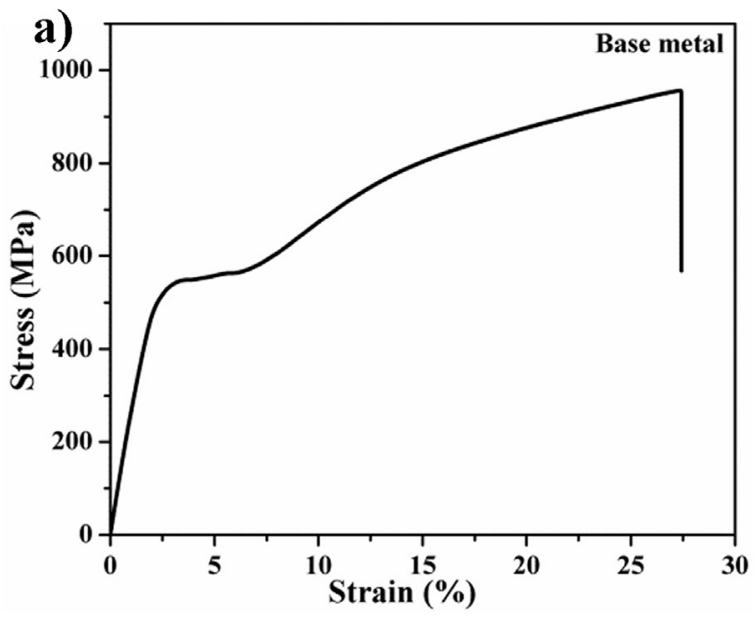

b)
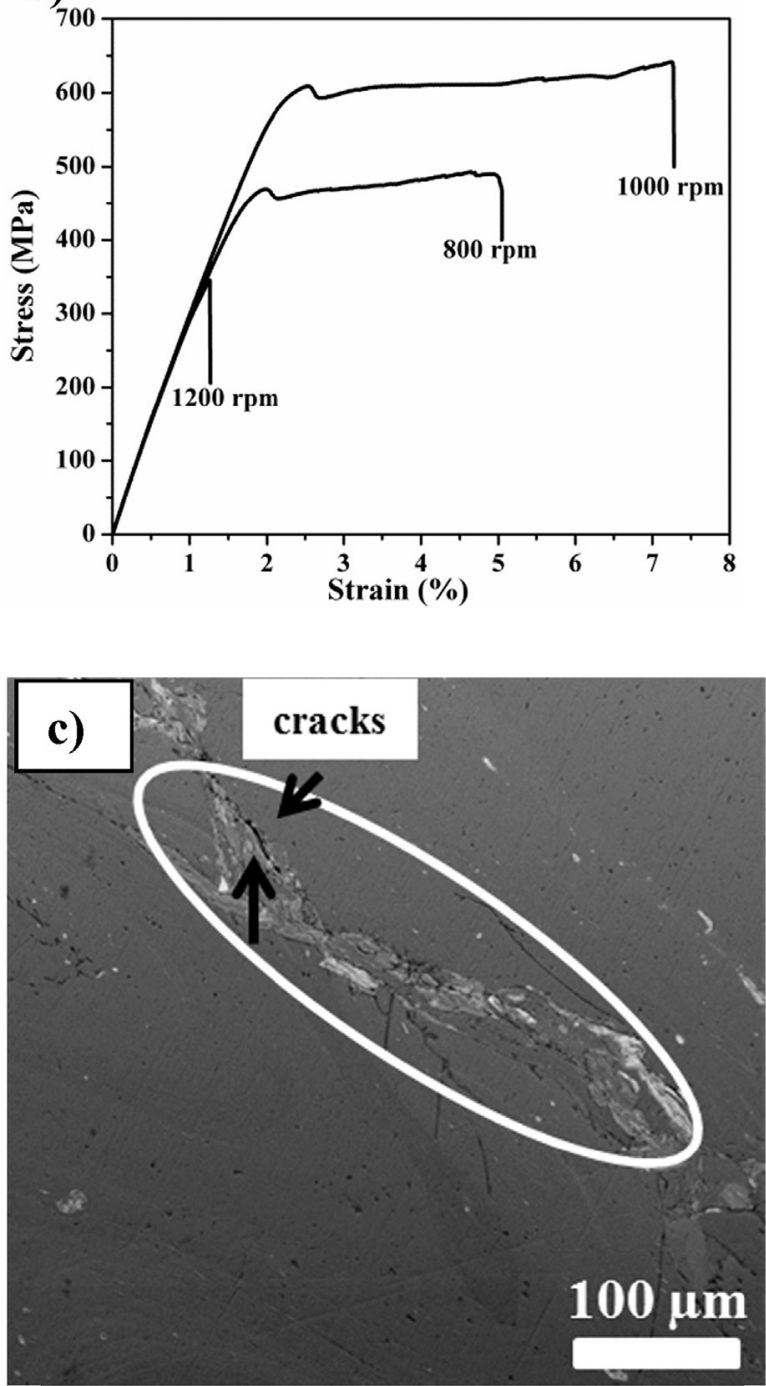

Fig. 10. a) Engineering stress-strain plot of the base metal, b) Engineering stress-strain plot of the welds and c) Cross sectional SEM images of the weld at $1200 \mathrm{rpm}$ showing cracks. 

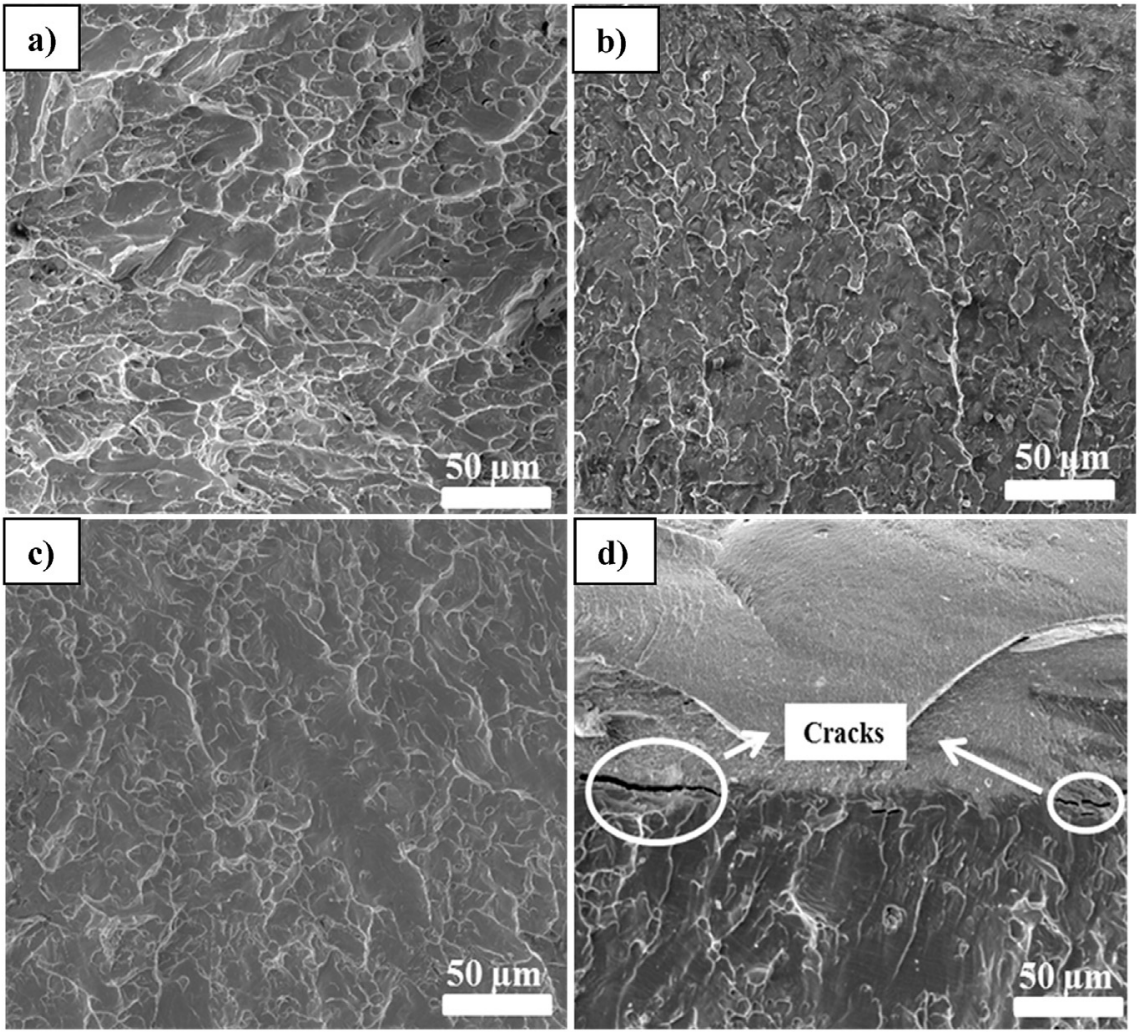

Fig. 11. Fracture surfaces of the tensile specimen a) Base metal, b) weld at $800 \mathrm{rpm}, \mathrm{c}$ ) weld at $1000 \mathrm{rpm}$ and d) weld at $1200 \mathrm{rpm}$.



Fig. 12. DSC curve of the annealed sample after welding.

\subsection{Simulation results based on FEM}

The governing equations mentioned in theoretical analysis section have been used for simulation. Based on the same model, the temperature distribution during FSW of stainless steel and aluminum was reported $[38,39]$. The welding parameters mentioned in Fig. 1 and the material properties of tool and work piece has been used for simulation. The temperature distribution at different tool rotational speed is shown in Fig. $14 a-c$. The increase in tool rotation speed has increased the maximum temperature during welding. The FSW at $1200 \mathrm{rpm}$ has shown a highest temperature of $1094^{\circ} \mathrm{C}$. The maximum temperature was recorded in the edge of the pin on the advancing side. The advancing side has shown higher temperature than the retreating side for all the tool rotational speeds. The temperature of the weld at different points across the weld viz. nugget center (NC), peak temperature (PT), advancing side (AS) and retreating side (RS) is shown in Fig. 14d and e. The temperature data from the simulation further corroborates the DSC results and microstructural results i.e. with increasing rotational speed the material is subjected to higher temperatures resulting coarsening of grains leading to greater drift in transformational temperatures. Further, drift in transformational temperatures within a weld can be attributed to variation in temperature experienced by each region.

\section{Conclusions}

The FSW of NiTi SMA at three different rotational speeds has been carried out and the following conclusions are drawn.

FSW is a feasible method to join SMA as the weld has formed without intermetallics and the shape memory behavior was retained after welding. 
a)
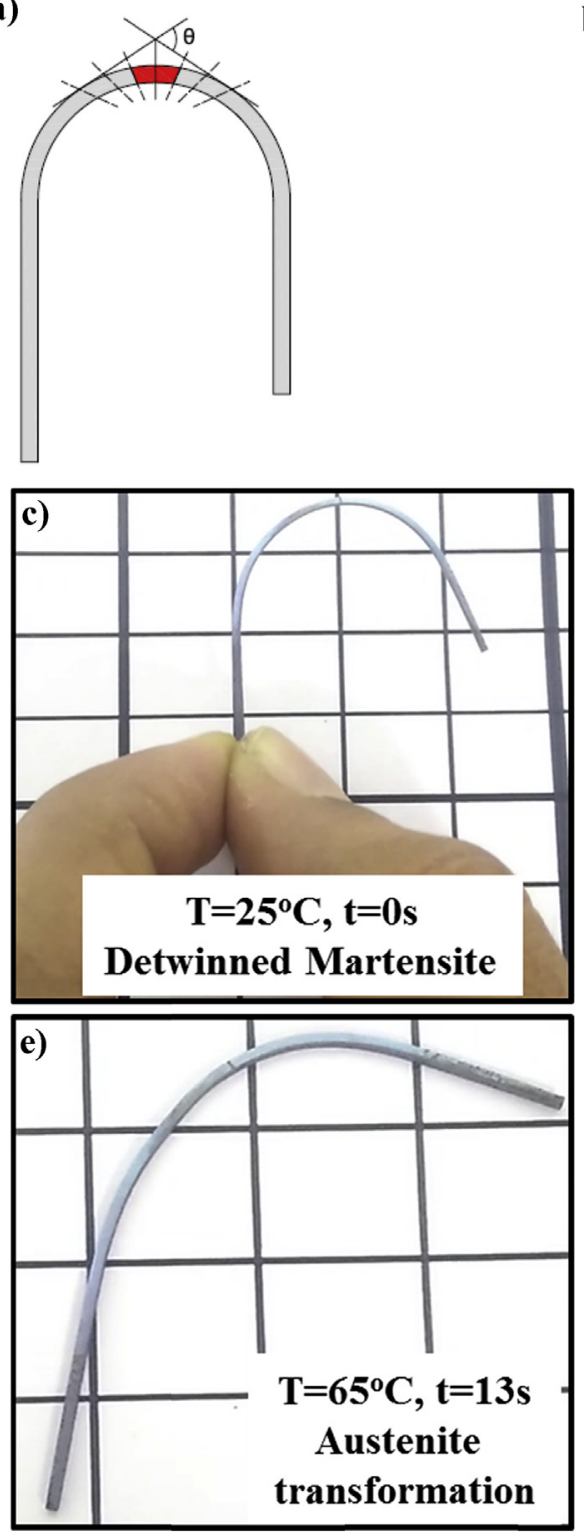

b)
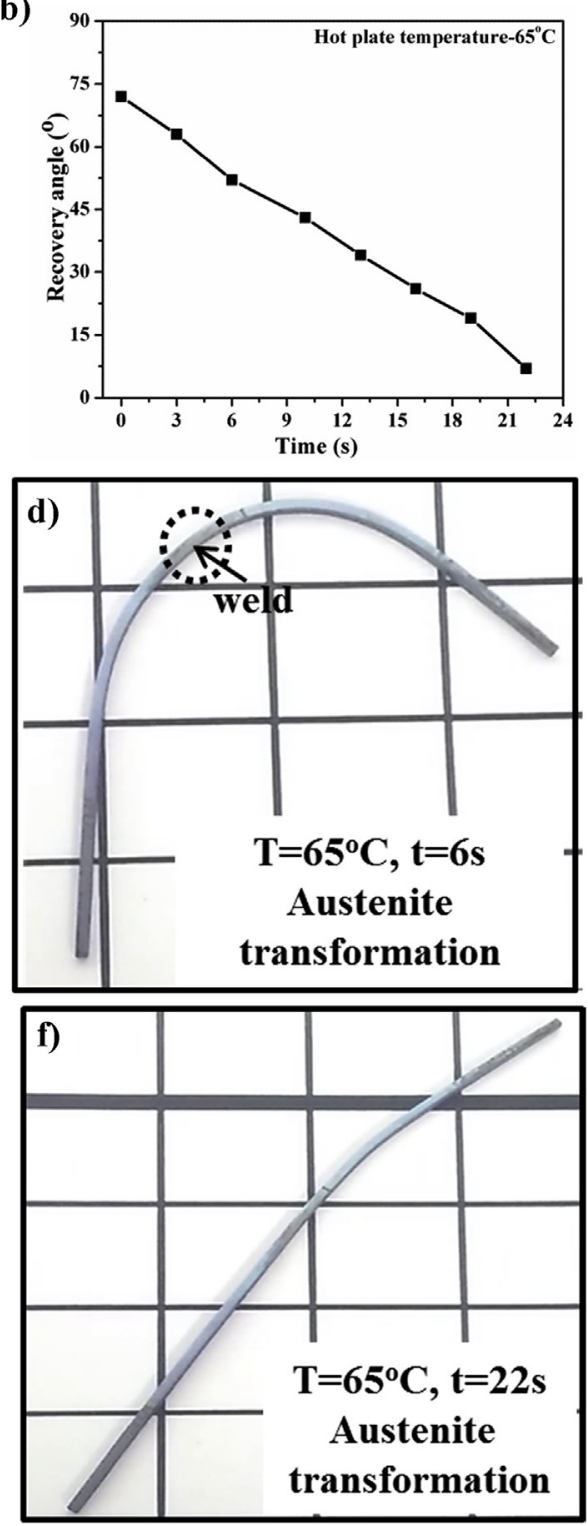

Fig. 13. a) schematic of angle measurement, b) recovery angle vs time plot and c)-f) Snapshots during actuation.

Recrystallized grain size in the nugget has increased with the increasing rotational speed due to considerable rise in peak temperature.

The phase transformation temperatures of the weld produced at $800 \mathrm{rpm}$ and base metal were near identical to the base metal. However, the welds at 1000 and $1200 \mathrm{rpm}$ have shown a marginal drift from the transformation temperatures of the base metal as they were significantly affected by high temperature during processing.
The asymmetry of weld condition across the weld has led to drift in transformation temperatures in nugget, advancing, and retreating sides.

The weld accomplished at $1000 \mathrm{rpm}$ has showed higher yield strength than the base metal and crucial superelastic plateau near $600 \mathrm{MPa}$.

The weld joint efficiency at $800 \mathrm{rpm}$ and $1200 \mathrm{rpm}$ was low and further optimization of welding parameters is required for improving the weld structural integrity. 

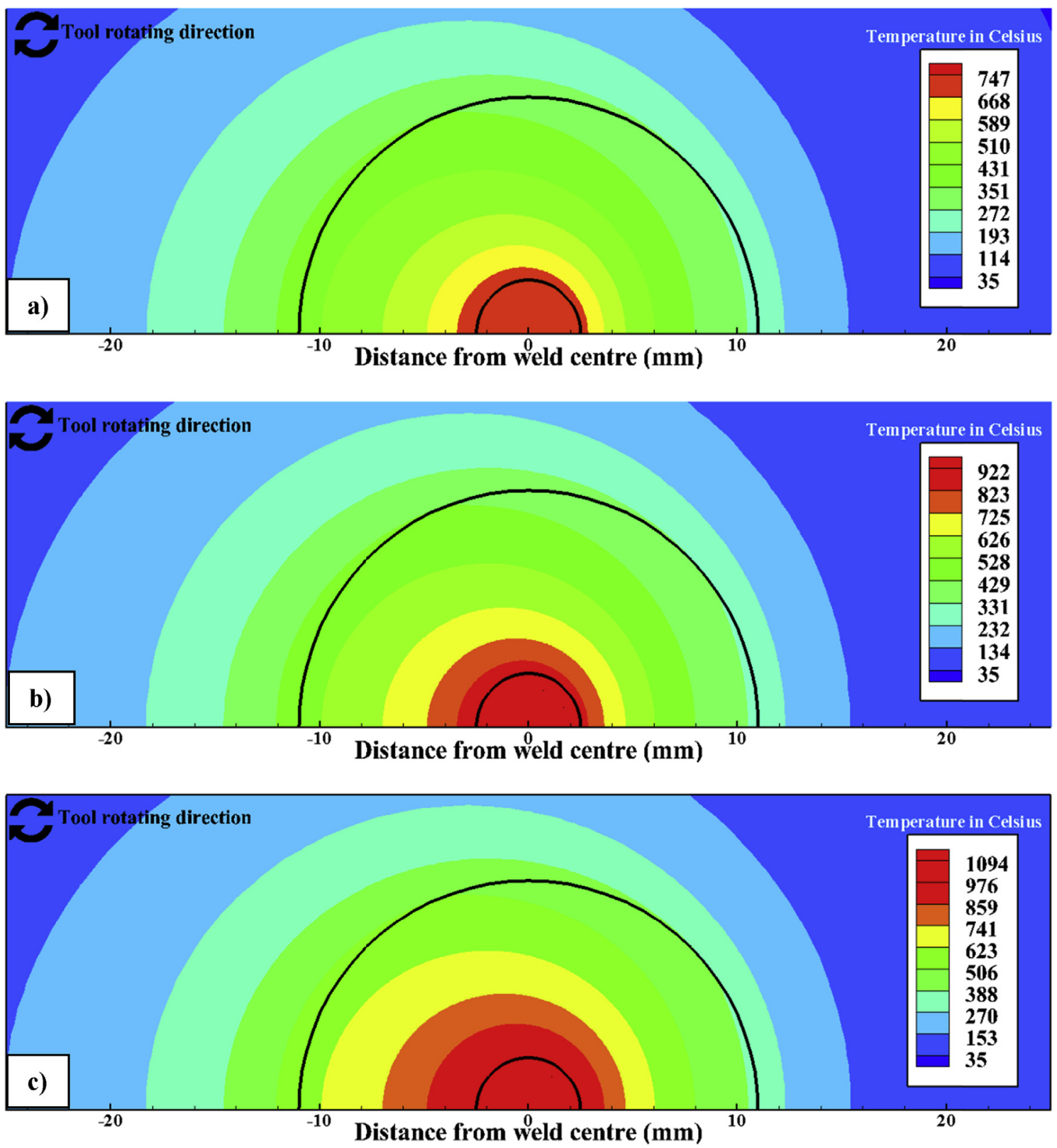

d)

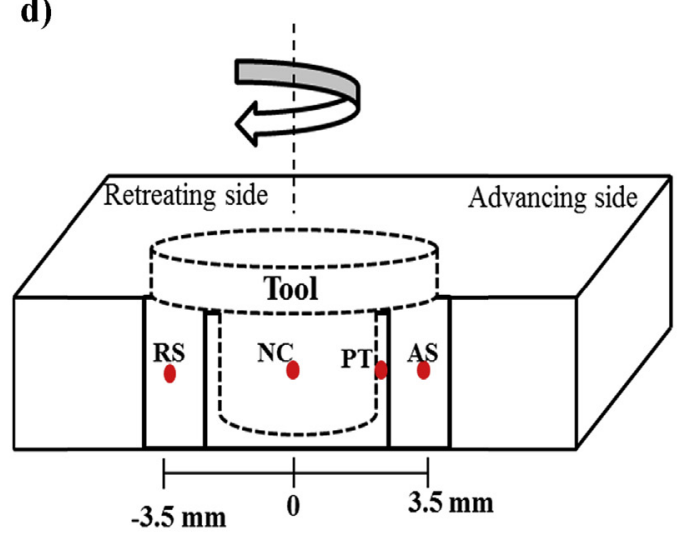

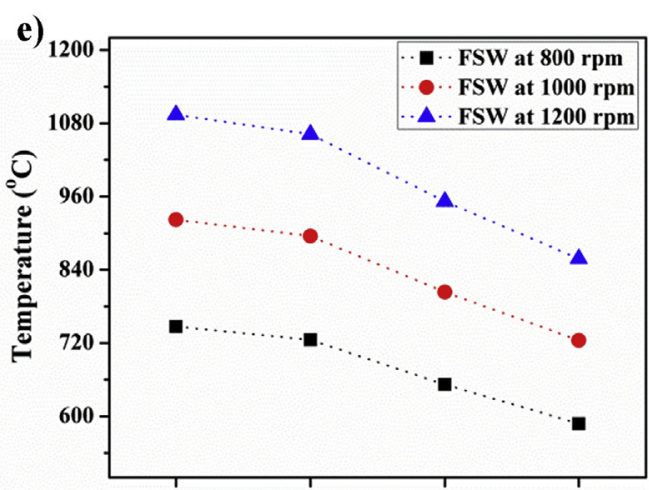

Peak Nugget Advancing Retreating Temperature Centre Side Side

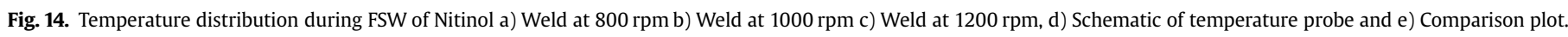




\section{Acknowledgments}

Authors are grateful to the Department of Materials Engineering of IISc Bangalore and sophisticated instrumentation center of IIT Indore for providing the required characterization facility for the successful completion of this work. The authors are grateful to Aditya K. Litoria of IIT Indore and A. N. Jinoop from RRCAT for their assistance in metallography sample preparation and characterization. The authors are thankful to Vijay Choyal, Ashish K. Shukla and Deepak Selvakumar of IIT Indore for their assistance in Comsol simulation. The authors also acknowledge the support from $\mathrm{M}$ Manikandan during actuation studies.

\section{References}

[1] J. Mohd Jani, M. Leary, A. Subic, M.A. Gibson, A review of shape memory alloy research, applications and opportunities, Mater. Des. 56 (2014) 1078-1113.

[2] J.J. Marattukalam, V.K. Balla, M. Das, S. Bontha, S.K. Kalpathy, Effect of heat treatment on microstructure, corrosion, and shape memory characteristics of laser deposited NiTi alloy, J. Alloys Compd. 744 (2018) 337-346.

[3] O.E. Ozbulut, S. Hurlebaus, R. Desroches, Seismic response control using shape memory alloys: a review, J. Intell. Mater. Syst. Struct. 22 (2011) 1531-1549.

[4] J.P. Oliveira, D. Barbosa, F.M.B. Fernandes, R.M. Miranda, Tungsten inert gas TIG ) welding of Ni-rich NiTi plates : functional behavior, Smart Mater. Struct. 25 (2016).

[5] E. Choi, S. Park, B. Cho, D. Hui, Lateral reinforcement of welded SMA rings for reinforced concrete columns, J. Alloys Compd. 577 (2013) S756-S759, https:// doi.org/10.1016/j.jallcom.2012.02.135.

[6] C. Van Der Eijk, H. Fostervoll, Z.K. Sallom, O.M. Akselsen, Plasma Welding of NiTi to NiTi, Stainless Steel and Hastelloy C276, 2003, pp. 13-15.

[7] C. Van Der Eijk, Z.K. Sallom, O.M. Akselsen, Microwave brazing of NiTi shape memory alloy with $\mathrm{Ag}-\mathrm{Ti}$ and $\mathrm{Ag}-\mathrm{Cu}-\mathrm{Ti}$ alloys, Scr. Mater. 58 (2008) 779-781, https://doi.org/10.1016/j.scriptamat.2007.12.017.

[8] V. Delobelle, P. Delobelle, Y. Liu, D. Favier, H. Louche, Resistance welding of NiTi shape memory alloy tubes, J. Mater. Process. Technol. 213 (2013) 1139-1145, https://doi.org/10.1016/j.jmatprotec.2013.01.013.

[9] D. Bharathi, T. Kannan, P. Sathiya, T. Ramesh, Experimental investigation and characterization of laser welded NiTinol shape memory alloys, J. Manuf. Process. 25 (2017) 253-261, https://doi.org/10.1016/j.jmapro.2016.12.006.

[10] X. Zhou, Y. Chen, Y. Huang, Y. Mao, Y. Yu, Effects of niobium addition on the microstructure and mechanical properties of laser-welded joints of NiTiNb and Ti6Al4V alloys, J. Alloys Compd. 735 (2018) 2616-2624.

[11] D. Yang, H.C. Jiang, M.J. Zhao, L.J. Rong, Microstructure and mechanical behaviors of electron beam welded NiTi shape memory alloys, Mater. Des. 57 (2014) 21-25, https://doi.org/10.1016/j.matdes.2013.12.039.

[12] J. Frenzel, E.P. George, A. Dlouhy, C. Somsen, M.F. Wagner, G. Eggeler, Influence of Ni on martensitic phase transformations in NiTi shape memory alloys, Acta Mater. 58 (2010) 3444-3458.

[13] J. Frenzel, A. Wieczorek, I. Opahle, B. Maaß, R. Drautz, G. Eggeler, On the effect of alloy composition on martensite start temperatures and latent heats in $\mathrm{Ni}-$ Ti-based shape memory alloys, Acta Mater. 90 (2015) 213-231.

[14] B. Tam, M.I. Khan, Y. Zhou, Mechanical and Functional Properties of Laserwelded Ti-55 . 8 Wt Pct Ni Nitinol Wires, 2011, https://doi.org/10.1007/ s11661-011-0639-6.

[15] S.S.M. Prabu, H.C. Madhu, C.S. Perugu, K. Akash, P.A. Kumar, Microstructure mechanical properties and shape memory behaviour of friction stir welded nitinol, Mater. Sci. Eng. A 693 (2017) 233-236, https://doi.org/10.1016/ j.msea.2017.03.101.

[16] G.K. Padhy, C.S. Wu, S. Gao, Friction stir based welding and processing technologies - processes, parameters, microstructures and applications: a review, J. Mater. Sci. Technol. 34 (2018) 1-38.

[17] S. Mironov, Y.S. Sato, H. Kokawa, Friction-stir welding and processing of Ti6Al-4V titanium alloy: a review, J. Mater. Sci. Technol. 34 (2018) 58-72.

[18] R.S. Mishra, Z.Y. Ma, Friction stir welding and processing, Mater. Sci. Eng. R. 50
(2005) 1-78, https://doi.org/10.1016/j.mser.2005.07.001.

[19] J. Cho, D.E. Boyce, P.R. Dawson, Modeling strain hardening and texture evolution in friction stir welding of stainless steel 398 (2005) 146-163, https:// doi.org/10.1016/j.msea.2005.03.002.

[20] R. Nandan, T. Debroy, H.K.D.H. Bhadeshia, Recent advances in friction-stir welding - Process, weldment structure and properties 53 (2008) 980-1023, https://doi.org/10.1016/j.pmatsci.2008.05.001.

[21] M. Pourali, A. Abdollah-zadeh, T. Saeid, F. Kargar, Influence of welding parameters on intermetallic compounds formation in dissimilar steel/aluminum friction stir welds, J. Alloys Compd. 715 (2017) 1-8, https://doi.org/10.1016/ j.jallcom.2017.04.272.

[22] H. Chen, L. Fu, P. Liang, Microstructure, texture and mechanical properties of friction stir welded butt joints of 2A97 Al-Li alloy ultra-thin sheets, J. Alloys Compd. 692 (2017) 155-169, https://doi.org/10.1016/j.jallcom.2016.08.330.

[23] M. Song, R. Kovacevic, Thermal modeling of friction stir welding in a moving coordinate system and its validation, Int. J. Mach. Tool Manufact. 43 (2003) 605-615, https://doi.org/10.1016/S0890-6955(03)00022-1.

[24] Y. Zhang, S. Jiang, L. Hu, Investigation of Dynamic Recrystallization of NiTi shape memory alloy subjected to local canning compression, Metals (Basel) (2017) 1-10, https://doi.org/10.3390/met7060208.

[25] K. Huang, R.E. Logé, A review of dynamic recrystallization phenomena in metallic materials, Mater. Des. 111 (2016) 548-574, https://doi.org/10.1016/ j.matdes.2016.09.012.

[26] T. Sakai, A. Belyakov, R. Kaibyshev, H. Miura, J.J. Jonas, Dynamic and postdynamic recrystallization under hot, cold and severe plastic deformation conditions, Prog. Mater. Sci. 60 (2014) 130-207, https://doi.org/10.1016/ j.pmatsci.2013.09.002.

[27] S. Dixit, H.C. Madhu, S.V. Kailas, K. Chattopadhyay, Role of insert material on process loads during FSW, Int. J. Adv. Manuf. Technol. (2017), https://doi.org/ 10.1007/s00170-016-9974-5.

[28] S. Jiang, Y. Zhang, Y. Zhao, Dynamic recovery and dynamic recrystallization of NiTi shape memory alloy under hot compression deformation, Trans. Nonferrous Metals Soc. China 23 (2013) 140-147, https://doi.org/10.1016/ S1003-6326(13)62440-1.

[29] Y.T. Hsu, Y.R. Wang, S.K. Wu, C. Chen, Effect of CO 2 laser welding on the shape-memory and corrosion characteristics of TiNi, Alloys 32 (2001) $569-576$.

[30] D.C. Lagoudas, Shape Memory Alloys:modelling and Engineering Applications, Springer, 2008

[31] H. Kato, Y. Yasuda, K. Sasaki, Thermodynamic assessment of the stabilization effect in deformed shape memory alloy martensite, Acta Mater. 59 (2011) 3955-3964.

[32] A. Evirgen, I. Karaman, R. Santamarta, J. Pons, C. Hayrettin, R.D. Noebe, Relationship between crystallographic compatibility and thermal hysteresis in $\mathrm{Ni}$ rich NiTiHf and NiTiZr high temperature shape memory alloys, Acta Mater. 121 (2016) 374-383.

[33] P. La Roca, L. Isola, P. Vermaut, J. Malarría, Relationship between grain size and thermal hysteresis of martensitic transformations in Cu-based shape memory alloys, Scr. Mater. 135 (2017) 5-9.

[34] D. Yang, H.C. Jiang, M.J. Zhao, L.J. Rong, Microstructure and mechanical behaviors of electron beam welded NiTi shape memory alloys, Mater. Des. 57 (2014) 21-25.

[35] Z. Zeng, M. Yang, J.P. Oliveira, D. Song, B. Peng, Laser welding of NiTi shape memory alloy wires and tubes for multi-functional design applications, Smart Mater. Struct. 25 (n.d.) 1-10.

[36] A.S. Zoeram, A. Rahmani, Characterization the microstructure of pulsed Nd: YAG welding method in low frequencies; correlation with tensile and fracture behavior in laser-welded nitinol joints, Smart Mater. Struct. (2017), 055030.

[37] J.P. Oliveira, F.M.B. Fernandes, N. Schell, R.M. Miranda, Shape memory effect of laser welded NiTi plates, Funct. Mater. Lett. 8 (2015) 1-5, https://doi.org/ $10.1142 /$ S1793604715500691.

[38] P. Chansoria, P. Solanki, M.S. Dasgupta, Parametric Study of Transient Temperature Distribution in FSW of 304L Stainless Steel, 2015, pp. 1223-1239, https://doi.org/10.1007/s00170-015-7102-6.

[39] V. vignesh R, P. R, A. M, G. S, J. Thirumalini, M.S.S.S. Ram, Numerical modelling of thermal phenomenon in friction stir welding of aluminum plates, IOP Conf. Ser. Mater. Sci. Eng. (2016), https://doi.org/10.1088/1757-899X/149/1/ 012208 . 